\title{
On the Edge of a New Perception: The Art of Moran and Watkins
}

\section{Lauren Ehrmann}

\author{
Faculty Mentor: Dr. Christoph Irmscher, Department of English Indiana University
}

$\mathrm{N}$ ear the end of the nineteenth century, technological advances had rendered it less perilous to cross the continent, and the United States began to consider in earnest the newly acquired and more sparsely populated territory on the other side of the Rocky Mountains known as the West. Scientific expeditions and entrepreneurial ventures began to flock westward, and with them came artists. Art was a central part of the process of understanding the West and conveying the nature of that portion of the nation to more populated areas in the East. The visual documentation of the American West has become an indelible part of American identity, and the artists first tasked with recording the landscapes that they encountered in the West faced important questions about the role of documentation. This has shaped how Americans view the West and how we view ourselves to this day. The Grand Canyon of the Yellowstone by Thomas Moran and The Grizzly Giant by Carleton Watkins are two artworks that provide a valuable lens through which to view these shifting perspectives on the role of art in the documentation, presentation, and preservation of landscape in the late nineteenth century.

In 1871, Ferdinand V. Hayden, a preeminent geologist and explorer, petitioned the U.S. government for funds to make an expedition into the region of the United States today known as Yellowstone National Park and take a geological survey of the area. ${ }^{1}$ He was accompanied by a large team, composed primarily of scientists, but among the members of his entourage was also the famous American landscape painter Thomas Moran. ${ }^{2}$ Moran, as the expedition's painter, was charged with creating scenes that accurately portrayed the sights he saw, particularly with respect to color. However, Moran also worked within the sublime landscape tradition that was well-established in the United States, and it is known that he altered many details of the landscapes he saw to make them more visually dynamic, and thus capture the spirit of the landscape rather than the landscape itself. This intersection of the scientific and the sublime puts the paintings produced during this expedition, particularly The Grand Canyon of the Yellowstone, at the heart of the questions surrounding the use of objectivity and emotion in documentation at the time.

In the late nineteenth century, the United States was increasingly turning toward science as the guiding ideal

\footnotetext{
1 "1871 Hayden Expedition," Yellowstone National Park, accessed October 23, 2016, http://www.yellowstonenationalpark.org/blog/yellowstone-history/1871-hayden-expedition/

${ }^{2}$ Angela L. Miller, Janet Catherine Benlo, and Jennifer L. Roberts, American Encounters: Art, History, and Culture (London: Prentice Hall, 2008),
} 303.

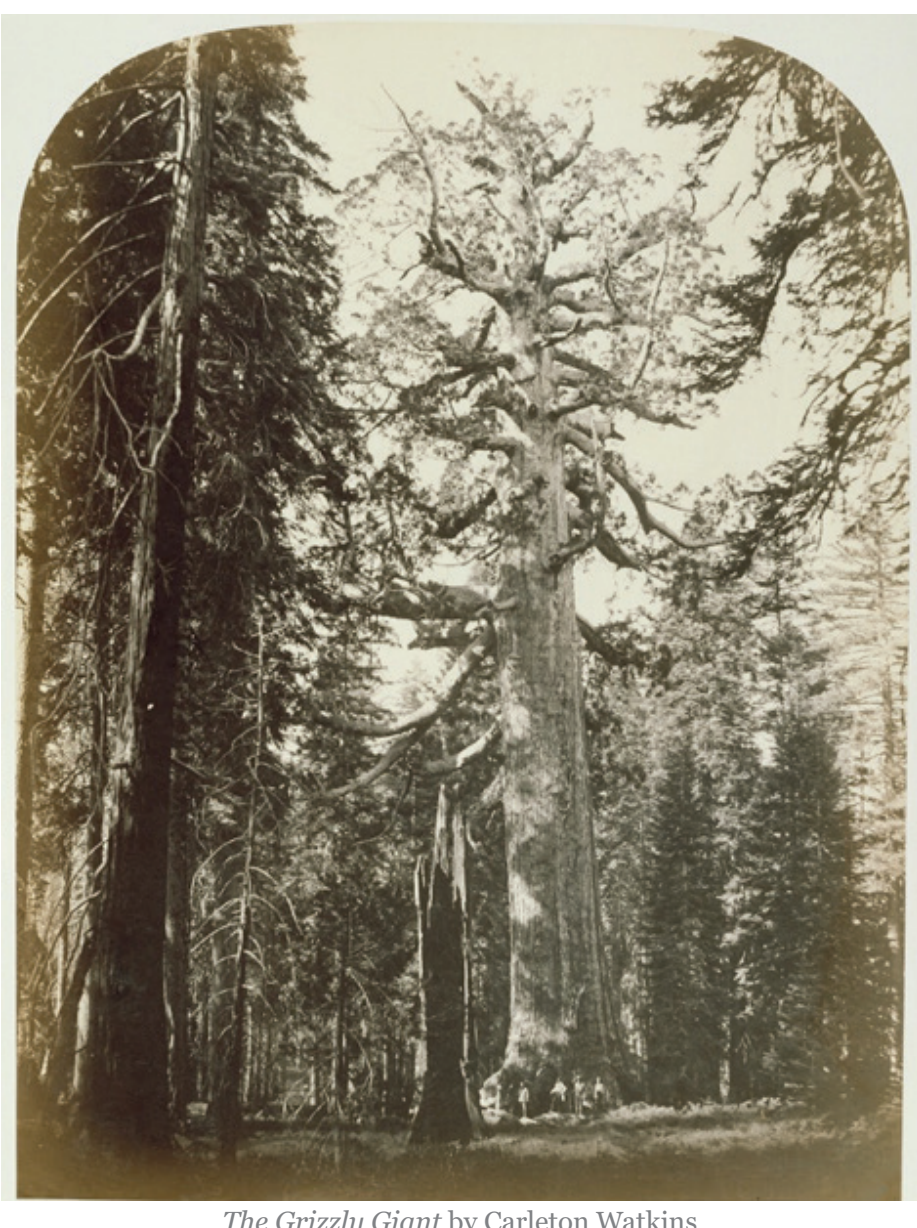

for a functioning society. Technological advancements such as electricity, the telegraph, and the steam engine were pushing American life forward, and Americans began to view technology, and by extension science, as the driving force behind the country's progress. ${ }^{3}$ Amid this wave of technological innovations, a new medium emerged that would change the way Americans viewed the world forever: photography. In the decades following its invention, photography was viewed not as an art form but as a method of objective and accurate visual documentation. ${ }^{4}$ Documentation had previously been the realm of fine art, especially painting, and now artists found themselves struggling to find the appropriate language for the representation of space. With straightforward

\section{${ }^{3}$ Ibid., 300}

${ }^{4}$ Ibid., 303 
documentation now consigned to the realm of science, artists began to emphasize the "atmosphere of spectacular nature," 5 or attempt to capture the experience of viewing nature rather than simply objectively reproduce it. They thus realized that even this traditional medium, while not inherently "scientific," could contribute to the new vogue for accuracy.

In his painting The Grand Canyon of the Yellowstone, Moran utilizes both documentation and emotion. Even though there was a photographer on the expedition, Moran still had a commitment to scientific documentation in his paintings because only a painter could capture color. $^{6}$ As Hayden himself says in the preface to a book of chromolithographs of Moran's paintings, "all reproductions of landscape scenery must necessarily lose the greater part of their charm when deprived of color; but of any representation in black and white of the scenery of Yellowstone it may truly be said that it is like Hamlet with the part of Hamlet omitted." ${ }^{\text {M }}$ Moran certainly emphasized color in the composition, depicting an enormous range of colors from deep purples to chalky yellows streaking the Canyon walls; his painting is an invaluable scientific document of the specific pigments found within the Yellowstone Canyon. ${ }^{8}$

The Grand Canyon of the Yellowstone makes a further argument for science in a symbolic sense. Moran depicts four figures, two of which are standing on a ledge overlooking the canyon. These figures serve many artistic purposes: they preserve a sense of scale and allow the viewer to imagine herself in the scene, viewing the landscape as if she were beside the figures depicted. But they also serve an allegorical purpose: one figure is a member of the geological survey while the other is a Native American. ${ }^{9}$ Here, Moran symbolizes a peaceful handoff between the caretakers of the land. The Native American, a former custodian of this wilderness, faces the viewer while the scientist looks out across the landscape, already claiming it as his to explore, use, and protect. Moran makes a strong argument for science by allowing a member of a scientific survey to represent the progress and future of the American landscape.

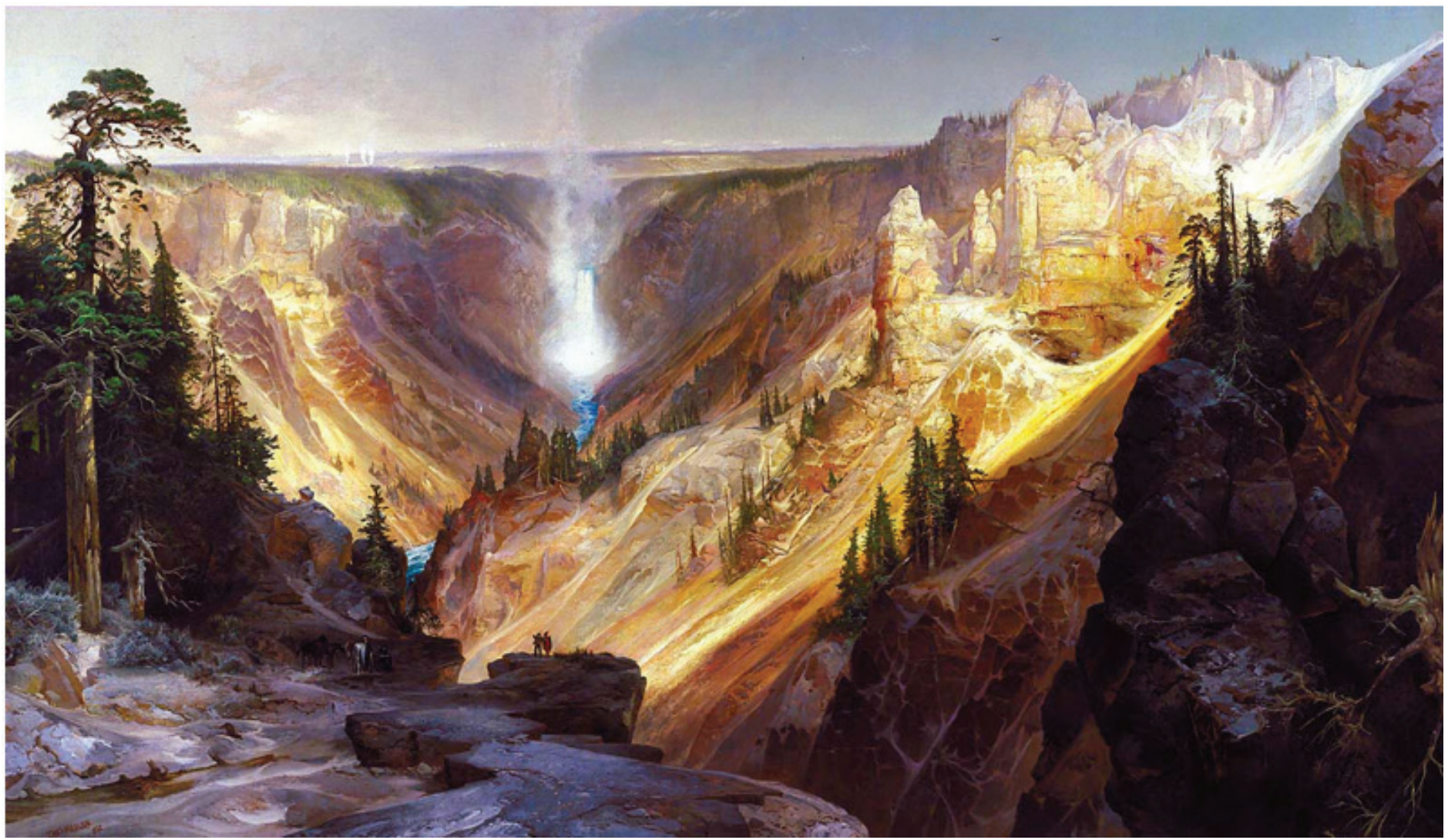

The Grand Canyon of the Yellowstone by Thomas Moran

${ }^{5}$ Sarah Wilson, "A Photograph and a Painting: William Henry Jackson, Thomas Moran, and Capturing Yellowstone Vistas," Wordpress (blog), February 11, 2016, https://theamericanistdiversion.com/2016/02/11/a-photograph-and-a-painting-william-henry-jackson-thomas-moran-and-capturing-yellowstone-vistas/. ${ }^{6}$ Ferdinand V. Hayden, The Yellowstone National Park and the Mountain Regions of Idaho, Nevada, Colorado and Utah, (L. Prang and Company, 1876), III.

${ }^{7}$ Ibid. 
Scientific accuracy, however, is not Moran's sole goal, or even his primary goal. In a letter from Moran to Hayden, he states that with Canyon he hopes to "produce a most decided sensation in Art Circles;" 10 in other words, Moran hopes to emphasize emotion (or "sensation") in this painting. To that end, he turns to the time-honored tradition of the sublime. Edmund Burke, in his book $A$ Philosophical Enquiry into the Origin of our Ideas of the Sublime and Beautiful, defines the sublime as "whatever is fitted...to excite ideas of pain and danger, ... whatever is in any sort terrible ... is a source of the sublime, that is, productive of the strongest emotion which the mind is capable of feeling." 11 The sublime is the union of terror and beauty, a perfect visual language for conveying the excitement and discomfort of progression (in competition with photography) as well as tying the composition to a much older artistic tradition. In Canyon, Moran uses, to great effect, many of the elements which Burke outlines in his book as producing the sublime. The sublime centers around terror, and Burke lists "vastness" and "infinity" as two devices by which this terror may be conveyed. ${ }^{12}$ Moran expertly depicts a heady sense of vastness with the high vantage point and the large size of the canvas. He presents a seemingly infinite vista by fading the edges of the landscape at the horizon line, suggesting that the landscape presented to the viewer could well go on forever. Furthermore, Moran creates a heightened sense of terror and appeals to the viewer's instinct of self-preservation by placing the two central figures in the painting at the edge of a sheer vertical drop - the viewer puts herself in the shoes of these figures and experiences the landscape from the viewpoint of a cliff edge.

Another cause of the experience of the sublime is irregularity and asymmetry, ${ }^{13}$ both used by Moran in this composition. The edges and surface of Yellowstone Canyon are jagged and irregular, and a cluster of pine trees on the left of the composition creates asymmetry, despite the fact that no such asymmetry exists from this vantage point in real life - it was created by Moran to heighten the effect of the sublime. By using these elements, Moran supports the argument that a landscape is more than merely the sum of its parts. To truly capture a landscape, one has to do more than simply restate visual facts; an artist must capture what it feels like to stand in that space and convey some of that overwhelming and terrifying awe in his painting. By being able to incorporate emotional experience into documentation, painting makes itself perhaps an even more valuable record of a space than photography, in that it captures the experience of a landscape rather than mere

\footnotetext{
${ }^{10}$ Wilson, "A Photograph and a Painting."

${ }^{11}$ Edmund Burke, A Philosophical Inquiry into the Origin of Our Ideas of the Sublime and Beautiful, (Columbia University Press, 1958), 39.

${ }^{12}$ Ibid., 72-73.

${ }^{13}$ Ibid., 83.
}

topography.

While Moran's The Grand Canyon of the Yellowstone makes an argument for the continued importance of painting in landscape documentation, it is interesting to note that paintings such as Moran's from Yellowstone would not have been credible without the advent of photography. Without the objective proof of a photograph, the general public would not have accepted the fantastic scenery that Moran captures as anything more than a figment of his imagination. ${ }^{14}$ One of the central roles of photographers in the West was proving that such places did indeed exist, and there is no better example of this than Carleton Watkins's famous The Grizzly Giant, a photograph of one of California's oldest giant sequoias taken in 1865. Like Moran, Watkins worked during the time shortly after the creation of photography, during which the definition of both art and documentation were in flux. Watkins was working with a new medium that was in the process of defining its role in the world of art and science. Viewed in this context, Watkin's work as a whole, and specifically Grizzly Giant, make an argument that photography belongs to both worlds: the world of empirical documentation and the world of artistic expression.

Just like Moran, Watkins expresses this argument by combining elements of scientific observation with sublime composition. Watkins was not involved in any official scientific expeditions or surveys at this time, but he was highly aware that by dint of his medium, much of the public would view his work as scientific, objective evidence of the existence of his chosen subject. He selected his subjects accordingly, choosing scenes which would have been believed to be impossible if not for the objective proof of photography, capturing the natural rock formations and botanical marvels of California that could not be found in the East. ${ }^{15}$ Grizzly Giant is perhaps the best example of a photograph being used to convince people of the reality of the natural marvels of the West. Watkins used a custommade camera that could expose "mammoth" glass plates in order to capture the expansive vistas of the West, and this technique meant that he was the first photographer ever to be able to capture the entirety of a giant sequoia on film. ${ }^{16}$ The photo created awareness of the existence of these enormous trees to such a degree that Ralph Waldo Emerson said of Grizzly Giant that it "made the tree possible."17 In other words, Grizzly Giant shows how the documentative, scientific property of photography lent the narrative of the West credibility and was instrumental

\footnotetext{
${ }^{14}$ Joni Kinsey, Thomas Moran's West: Chromolithography, High Art, and Popular Taste (Lawrence: University Press of Kansas, 2006).

15 "Art and the Hayden Geological Survey of 1871," Smithsonian American Art Museum, accessed October 27, 2016, http://americanexperience.si.edu/wp-content/uploads/2015/02/Art-and-the-Hayden-Geological-Survey-of-1871_.pdf.

${ }^{16}$ Mark Pimlott, Without and Within: Essays on Territory and the Interior (Rotterdam: Episode Publishers, 2007), 74.
} 
to allowing the West to occupy its place in the American imagination at the time.

At first glance, Grizzly Giant appears to be a photograph whose only goal is documentation, concerned solely with getting the entirety of the massive sequoia into the frame without any other artistic considerations. But longer contemplation of the photograph will reveal that many artistic choices were made to cast this giant sequoia into the role in which Watkins wishes it to be viewed. Like Moran, when it comes to the artistic elements of this photograph, Watkins chooses to use the language of the sublime, the aesthetic format which has long colored the way Americans think about landscape and wilderness. Once again, Burke's Enquiry provides a useful framework with which to analyze the elements of the sublime that are present in this work of art. Like Moran, Watkins emphasizes vastness, one of the traits of the sublime, to create a feeling of both awe and terror. ${ }^{18} \mathrm{He}$ highlights the vastness of the giant sequoia by positioning a group of men in a cluster at the bottom of the tree to indicate scale, showing how truly massive the tree is. Another aspect of the sublime that Burke captures in this photograph is power. ${ }^{19}$ The men positioned at the base of the tree are likely a group of explorers, one of whom is identifiable from another photograph taken of the same tree as Galen Clark, caretaker of this grove of giant sequoias and identifiable to Americans at the time as a famous "wilderness man." 20 Clark, a large man physically and an even larger figure in the American imagination, is nevertheless dwarfed in this photo by the tree, indicating the even greater power that the tree possesses. ${ }^{21}$ Finally, the irregular and asymmetric are causes of feelings of the sublime. ${ }^{22}$ Watkins clearly emphasizes the rough, irregular texture of the tree and its many twisted branches, which suggest that the tree has survived a calamity. Watkins is famous for using a wet plate development process that gave his photographs remarkable crispness, rendering the textures of the giant sequoia with great clarity. ${ }^{23}$ Watkins' desire to connect this photograph to the tradition of the sublime is further made evident by his choice of title: Grizzly Giant. "Grizzly" points not only to the sublime irregularity of the build and texture of the tree, but also to the sublime feelings inspired by the memory of past storms which have shaped the tree. "Giant" evokes sublime ideas of vastness, infinity, and power; the tree Watkins depicts is giant not only in the physical sense but also in the way it plays upon

\footnotetext{
${ }^{17}$ Ibid., 72.

${ }^{18}$ Burke, A Philosophical Inquiry, 72.

${ }^{19}$ Ibid., 64-70.

${ }^{20}$ Elizabeth Hutchinson, "They Might Be Giants: Galen Clark, Carleton Watkins, and the Big Tree," in A Keener Perception: Ecocritical Studies in American Art History, ed. Alan Braddock, Christoph Irmscher, (University of Alabama Press, 2009), 117.

${ }^{21}$ Ibid., 116.

${ }^{22}$ Burke, A Philosophical Inquiry, 83.

${ }^{23}$ Pimlott, Without and Within, 72.
}

the viewer's ideas of the infinite. When a viewer sees an image of such a large tree, she immediately considers the vastness of time required for the tree to grow to such immense size, and in this way, Watkins portrays a tree that is vast both in size and in its place in history and the American psyche.

The audience of Grizzly Giant would have likely encountered this photograph in a bound collection of prints of Watkins's photographs of the area, ${ }^{24}$ although it was also on display in galleries. Interestingly, Moran's Canyon was distributed in much the same way, in a bound volume of chromolithographs printed by the famous chromolithographic company Prang and Co. To be able make color reproductions of paintings through chromolithography was a relatively recent event in the art world, one which many of Moran's contemporaries were embracing as well as a means of making their artwork available to a wider market. ${ }^{26}$ Moran began his career working in reproductions as an engraver, and this, combined with his awareness of the commercial success of photographic reproductions, is likely what inspired him to market the reproductions of this paintings. ${ }^{27}$ What is most interesting about the bound volumes of Watkins and Moran is that they were marketed in much the same way. Surviving correspondence between Ferdinand Hayden and Prang indicates that Prang wanted to emphasize the scientific importance of the publication, which he achieved by having Hayden write an introduction to the volume as well as a commentary on each chromolithograph which positioned them within the context of the scientific expedition. ${ }^{28} \quad$ By framing the resulting volume of chromolithographs, entitled Yellowstone National Park, as both a scientific and an artistic work, Prang hoped to attract buyers of both markets. Watson did much the same in his bound works, representing his photos as documentation of scientific and natural wonders as well as works of fine art, the latter role emphasized by the quality and expense of the volumes produced. ${ }^{29}$

The consideration of distribution and marketing angles sheds light on a third factor which shaped the works of Moran and Watkins in addition to science and the sublime: enterprise; in other words, a preoccupation with the resources of the West. In the late nineteenth century, a mania for enterprise seemed to have swept the nation, and the West was one of the areas in which this

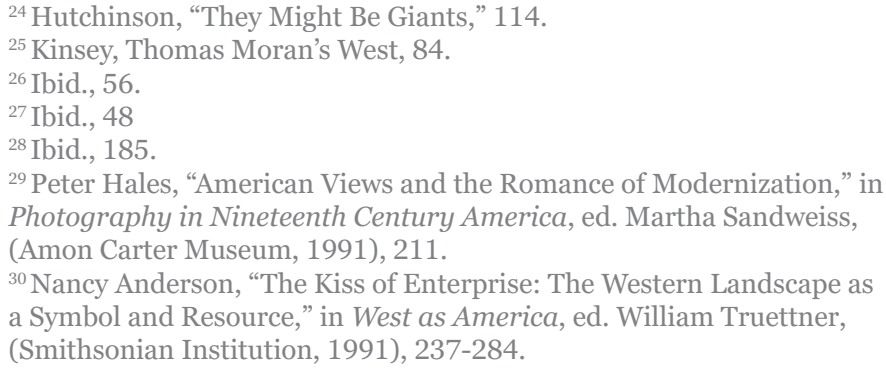


entrepreneurial sentiment was focused. ${ }^{30}$ Moran and Watkins chose to document the landscape of the West in such a way that conveyed both the resources present in the landscape and the ways in which the landscape itself was a resource.

At a strictly visual level, the matter of resources depicted in these paintings is fairly straightforward: both Moran and Watkins depicted extensive forests, indicating the wealth of lumber available in the American West and implying that other resources were equally plentiful. But the resource of the West that is the special focus of Moran and Watkins's work and is not immediately apparent because it is not one specific part of the scene they depict is the scene itself. The spectacular views of the West were themselves a resource. ${ }^{31}$ Like miners headed to the gold rush or loggers seeking to gain money from the West's forests, Moran and Watkins helped themselves to the region's most valuable resource: its landscapes. Scenes of the West were wildly popular, and artists recognized that they, too, could profit from the resources of the West. ${ }^{32}$ They mined the landscape using paintbrushes and cameras, and it yielded to them a profit that was both monetary and cultural. Framed in this way, it becomes evident that documentation of the West was shaped not only by scientific and artistic concerns, but also by an awareness of which compositions and scenes would be most popular with Eastern audiences.

The scenery of the West was valuable for another reason as well: it drew tourists in droves. By painting these scenes of the West and distributing them in more populated regions of the country, artists such as Moran and Watkins were instrumental in making the tourist industry in the West profitable. This is made all the more evident that throughout his career, Moran's various expeditions were almost invariably funded by railroad companies, who stood to gain the most from tourists interested in traveling West. ${ }^{33}$ Watkins, in turn, was financially dependent upon sales of his prints to tourists. ${ }^{34}$ Both Watkins and Moran are partially responsible for making the areas they photographed and painted, respectively, into national icons. Prior to the Hayden expedition and Moran's paintings, very little was known of the Yellowstone area. It was widely considered as a sulfurous hellhole. ${ }^{35}$ It became a popular tourist destination shortly after the debut of Moran's paintings in the East. Watkins's photographs, especially those of the giant sequoias such as Grizzly Giant and of Yosemite, put the area on the map for tourists from the East. ${ }^{36}$ More than simply depicting beautiful scenery, Moran and Watkins created lasting cultural icons of the areas they chose to depict.
The testament to the lasting impression of these artists works lies in far more than an increase in tourism to the areas they depicted, however. The artwork of both Moran and Watkins would become an essential part of convincing Congress to preserve the areas that were their chosen subject matter. Moran's sublime paintings together with the geological reports of Hayden and the lobbying of the railroads convinced Congress to preserve Yellowstone from further development in $1872 .{ }^{37}$ Perhaps not coincidentally, The Grand Canyon of the Yellowstone became the first landscape painting to be purchased by the U.S. government that same year. ${ }^{38}$ The photographs taken by Watkins that transformed Yosemite into a cultural icon were also passed around Congress in 1864 as part of the evidence used to garner support for the bill that made Yosemite inviolable. ${ }^{39}$

Moran's The Grand Canon of the Yellowstone and Watkin's Grizzly Giant sit at the intersection of major questions about perspective, documentation, enterprise, and preservation that were being asked in the late nineteenth century as the rapid pace of progress forced artists and the public to redefine what it meant to depict a landscape. By uniting science with the sublime, objective fact with subjective experience, and commercial endeavor with preservationist ethics, these pieces offer a view of the late nineteenth century in microcosm. They deal with questions about the struggle of artistic representation and the role it plays in shaping identity, enterprise, and culture - questions that have shaped visual culture in America and drastically changed the way in which we view the world around us and our place in it.

\section{AUTHOR INFORMATION}

All correspondence should be sent to the first author: lehrmann@iu.edu.

\section{BIBLIOGRAPHY}

Anderson, Nancy. "The Kiss of Enterprise: The Western Landscape as a Symbol and Resource.” In West as America, edited by William Truettner, 237-284. Smithsonian Institution, 1991.

Burke, Edmund. A Philosophical Inquiry into the Origin of Our Ideas of the Sublime and Beautiful. Columbia University Press, 1958.

Hathaway, Bruce. "About Carleton Watkins." Smithsonian. July 2008, accessed 14 December 2016. http:// www.smithsonianmag.com/history/about-carletonwatkins-116195/.

\footnotetext{
${ }^{31}$ Ibid., 238-239.

${ }^{32}$ Ibid.

${ }^{33}$ Ibid., 247.

34 "Carleton Watkins: Art and Perception," National Gallery of Art, accessed 14 December 2016, http://www.nga.gov/exhibitions/watkinsbro. htm.

${ }^{35}$ Kinsey, Thomas Moran's West, 60.

${ }^{36}$ Hutchinson, "They Might Be Giants," 121.

37 "Art and the Hayden Geological Survey of 1871."

${ }^{38}$ Miller, American Encounters, 304.

39 "Art and the Hayden Geological Survey of 1871." 
Hales, Peter. "American Views and the Romance of Modernization." In Photography in Nineteenth Century America, edited by Martha Sandweiss, 204257. Fort Worth: Amon Carter Museum, 1991.

Hayden, Ferdinand V. The Yellowstone National Park and the Mountain Regions of Idaho, Nevada, Colorado and Utah. L. Prang and Company, 1876.

Hutchinson, Elizabeth. "They Might Be Giants: Galen Clark, Carleton Watkins, and the Big Tree.” In A Keener Perception: Ecocritical Studies in American Art History, edited by Alan Braddock, Christoph Irmscher, 109-128. Tuscaloosa: University of Alabama Press, 2009.

Kinsey, Joni. Thomas Moran's West: Chromolithography, High Art, and Popular Taste. Lawrence: University Press of Kansas, 2006.

Miller, Angela L., Janet Catherine Benlo, and Jennifer L. Roberts. American Encounters: Art, History, and Culture. Prentice Hall, 2008.

Moran, Thomas. 1872. The Grand Canon of the Yellowstone. Oil on canvas. Washington D.C.: Smithsonian American Art Museum.

Pimlott, Mark. Without and Within: Essays on Territory and the Interior. Episode Publishers, 2007.

Wilson, Sarah, "A Photograph and a Painting: William Henry Jackson, Thomas Moran, and Capturing Yellowstone Vistas," Wordpress (blog), February 11, 2016, https://theamericanistdiversion. com/2016/02/11/a-photograph-and-a-paintingwilliam-henry-jackson-thomas-moran-and-capturingyellowstone-vistas/.

“1871 Hayden Expedition.” Yellowstone National Park. Accessed 23 October 2016. http://www. yellowstonenationalpark.org/blog/yellowstonehistory/1871-hayden-expedition/.

"Art and the Hayden Geological Survey of 1871." Smithsonian American Art Museum. Accessed 27 October 2016. http://americanexperience.si.edu/ wp-content/uploads/2015/02/Art-and-the-HaydenGeological-Survey-of-1871_.pdf.

"Carleton Watkins: Art and Perception." National Gallery of Art. Accessed 14 December 2016. http://www.nga. gov/exhibitions/watkinsbro.htm. 